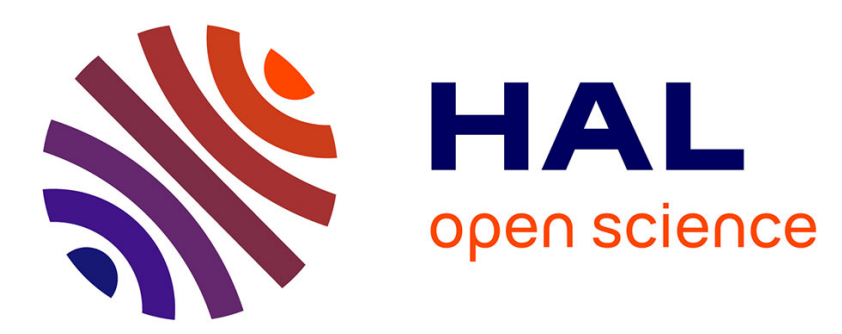

\title{
Characterization of Sol-Gel derived scintillating LuBO3 films doped with rare earth ions.
}

Christelle Mansuy, Eric Tomasella, Rachid Mahiou, Leon Gengembre, Jean

Grimblot, Jean-Marie Nedelec

\section{- To cite this version:}

Christelle Mansuy, Eric Tomasella, Rachid Mahiou, Leon Gengembre, Jean Grimblot, et al.. Characterization of Sol-Gel derived scintillating LuBO3 films doped with rare earth ions.. Thin Solid Films, 2006, 515, pp.666-669. 10.1016/j.tsf.2005.12.235 . hal-00154764

HAL Id: hal-00154764

https://hal.science/hal-00154764

Submitted on 14 Jun 2007

HAL is a multi-disciplinary open access archive for the deposit and dissemination of scientific research documents, whether they are published or not. The documents may come from teaching and research institutions in France or abroad, or from public or private research centers.
L'archive ouverte pluridisciplinaire HAL, est destinée au dépôt et à la diffusion de documents scientifiques de niveau recherche, publiés ou non, émanant des établissements d'enseignement et de recherche français ou étrangers, des laboratoires publics ou privés. 


\title{
Characterization of Sol-Gel derived scintillating $\mathrm{LuBO}_{3}$
}

\section{films doped with rare earth ions.}

\author{
C. Mansuy ${ }^{1}$, E. Tomasella ${ }^{1}$, L. Gengembre ${ }^{2}$, J. Grimblot $^{2}$, R. Mahiou ${ }^{1}$ and \\ J.M. Nedelec ${ }^{1 *}$ \\ 1 Laboratoire des Matériaux Inorganiques, CNRS UMR 6002, Université Blaise Pascal et \\ Ecole Nationale Supérieure de Chimie de Clermont-Ferrand, \\ 63177 Aubière Cedex, France
}

2 Laboratoire de Catalyse Homogène et Hétérogène CNRS UMR 8010

Université des Sciences et Technologies de Lille

59655 Villeneuve d'Ascq Cedex, France

\footnotetext{
* Corresponding author : Dr J.M. Nedelec

Laboratoire des Matériaux Inorganiques UMR 6002

Université Blaise Pascal, 24 Avenue des Landais

63177 Aubière Cedex, FRANCE

Fax : 0033473407108

E-mail : j-marie.nedelec@univ-bpclermont.fr
} 


\begin{abstract}
Rare earth doped $\mathrm{LuBO}_{3}$ thin films have been prepared by combining sol-gel process and coatings techniques such as spin coating and spray pyrolysis. Annealing treatment results in the crystallization of the film as vaterite phase and incorporation of the doping ions in solid solution. XPS and RBS spectrocopies showed that the composition of the films is close to the nominal one. Adventitious carbon has been observed and attributed to incomplete pyrolysis of metal-organic precursors. XPS concentrations profiles show a good homogeneity for the films. RBS demonstrated some inter-diffusion between amorphous carbon substrate and borate films resulting in a gradient of carbon at the interface between the substrate and the film itself. Finally scintillation spectra have been recorded and demonstrate the potentiality of these films to be used as X-ray intensifying screens.
\end{abstract}

PACS: 78.55.Hx, 81.15.Rs, 81.20. Fw, Keywords : Sol-Gel, Scintillators, XPS, RBS, Rare earth ions, Luminescence 


\section{Introduction}

The development of efficient scintillating materials is a very active area. It has been demonstrated in the past few years that sol-gel chemistry constitutes an interesting alternative to solid state preparation of scintillators $[1,2]$. Among the various advantages of using the solgel process, the possibility to prepare easily thin films from the solution is very attractive [3]. The high homogeneity of the sol-gel derived films coupled with the low processing cost associated with techniques like dip or spin coating or spray pyrolysis makes this technique suitable for industrial purposes. In the case of scintillators, the possibility to prepare high optical quality scintillating thin films is very valuable from the application point of view. In effect, such films would theoretically show very little scattering and thus higher resolution for imaging applications. Furthermore, the transparency of these thin films allows detecting the converted light in the transmission configuration which is very interesting for designing efficient and compact detecting systems. These thin scintillating films will also be of great interest for some fundamental studies such as absorption measurements in high energy range.

Due to its high density and high damage threshold, lutetium orthoborate $\mathrm{LuBO}_{3}$ has been considered as a promising host matrix for rare earth ions to produce phosphors, lasers or scintillators $[4,5]$. In particular $\mathrm{Ce}^{3+}$ doped $\mathrm{LuBO}_{3}$ is a very efficient scintillator. An original sol-gel route has been developed in our laboratory for the elaboration of rare earth orthoborates [6] and scintillation properties of sol-gel derived $\mathrm{Ce}^{3+}$ doped $\mathrm{LuBO}_{3}$ powders have been reported recently [7].

In this paper, we report on the characterization of sol-gel derived $\mathrm{LuBO}_{3}$ thin films doped with rare earth ions. X-ray Photoelectron Spectroscopy (XPS) and Rutherford Backscattering Spectroscopy (RBS) have been used to check the composition of the films and to confirm the effective doping with rare earth ions. Profiles recording during XPS measurements give us some information on the homogeneity of the films, whereas modeling of the RBS curve 
brings evidence for diffusion during the annealing process. Some scintillation results are also presented.

\section{Experimental section}

\subsection{Films preparation}

$\mathrm{LuBO}_{3}$ sol, used for the elaboration of the films, had been prepared by a sol-gel process described elsewhere [6]. In a first step, Lutetium and Ln chlorides $(\mathrm{Ln}=\mathrm{Ce}$ or Eu) are dissolved in required amounts in isopropanol during 2 hours. Doping ions concentrations have been chosen according to previous results obtained on sol-gel derived powders that showed maximum X-ray conversion efficiency for $\mathrm{Eu}^{3+}$ concentration of $5 \%$ and $\mathrm{Ce}^{3+}$ concentration of $0.5 \%$. Rare earth chlorides and solvents used were anhydrous and of high purity and all the experiments were carried out in an argon atmosphere in order to avoid hydrolysis of the alcoxides on contact with atmospheric humidity. Potassium isopropanolate is then prepared by reacting metallic potassium with isopropanol. After dissolution of chlorides, the solution of potassium isopropoxide is added. Thus, the chlorides mixture is reacted with the potassium alcoholate that substitutes for chloride leading to the formation of the rare earth alkoxides and the immediate precipitation of $\mathrm{KCl}$. The general scheme can be summarize as following:

$$
\mathrm{LnCl}_{3}+3 \mathrm{~K}^{+}+3{ }^{\mathrm{i}} \mathrm{OPr}^{-} \rightarrow \mathrm{Ln}\left({ }^{\mathrm{i}} \mathrm{OPr}\right)_{3}+3 \mathrm{KCl}
$$

The mixture is then refluxed for 2 hours at $85^{\circ} \mathrm{C}$ in order to complete the formation of the rare earth alkoxides. Finally, a solution of boron tri-isopropoxide is added. The mixture is stirred during 4 h-reflux at $85^{\circ} \mathrm{C}$.

Centrifugation is performed after cooling in order to eliminate $\mathrm{KCl}$. The sol is then used for the preparation of the films. In order to obtain xerogel powder, this sol is hydrolyzed with water, and the resulting gel is dried at $80^{\circ} \mathrm{C}$. The dry gel is then annealed at $800^{\circ} \mathrm{C}$ for $18 \mathrm{~h}$ to obtain $\mathrm{LuBO}_{3}$ crystalline powder. 
Two different techniques were used for the elaboration of the $\mathrm{LuBO}_{3}$ films: the spin coating and the spray coating.

The first one allows the elaboration of films which are thins and of good optical quality. Whereas, the films elaborated by spray coating are thicker but their quality is lower than the ones prepared by spin coating. This kind of thick films is required for the scintillation measurements where an important thickness is necessary in order to absorb a maximum of the incident light.

The spin coating films have been deposited on silica substrate carefully cleaned following procedures detailed elsewhere [8]. The program used for the spin coating is the following: the first step, characterized by a slow rotation speed (200 rpm), allows depositing the sol at the middle of the substrate. Then, several 10 seconds steps are successively performed with a rotation speed of 1000, 2000, 3000, 4000, 5000 and $6000 \mathrm{rpm}$. Several coatings operations are necessary in order to have films with suitable thickness.

The solution used for the spray-coated films is prepared from the powder, which is dispersed in isopropanol. The solution concentration is $3.5 \mathrm{~g} / \mathrm{L}$. In order to have a better dispersion of the powder, the solution is stirred in an ultrasound tank. This solution is then sprayed at a rate of about $2 \mathrm{~mL} \cdot \mathrm{min}^{-1}$, using a nitrogen flow, on a silica substrate heated at $150^{\circ} \mathrm{C}$. A coating consists of a 10 pulverizations serie in the horizontal direction and then in the vertical direction. Several coatings are carried out until desired thickness is obtained.

In both cases (spin and spray coating) a thermal treatment, during $10 \mathrm{~min}$ at $100^{\circ} \mathrm{C}$ and then at $600^{\circ} \mathrm{C}$, is necessary between each coating step. The complete densification of the film is performed by a final thermal treatment at $600^{\circ} \mathrm{C}$ for $1 \mathrm{~h}$.

\subsection{Characterization}

All samples have been checked by X-Ray diffraction on a Philips Xpert Pro operating with the $\mathrm{Cu}-\mathrm{K}_{\alpha}$ radiation $(\lambda=1.5406 \AA)$. 
X-ray photoelectron spectra were recorded using a VG Scientific 220XL Escalab. The monochromatized $\mathrm{Al} \mathrm{K}_{\alpha}$ source operated at $150 \mathrm{~W}$ (spot diameter $\sim 1 \mathrm{~mm}$ ). The energy analyser operated in a constant pass energy mode of $30 \mathrm{eV}$ using the magnetic mode facility. Due to the insulating character of the samples, an electron flood gun source of $6 \mathrm{~V}$ was applied to the samples during analysis to compensate the charging effect. The pressure in the analysis chamber was lower than $10^{-9}$ mbar. The binding energy scale was refereed to the position of the $\mathrm{C} 1 \mathrm{~s}$ line at $285 \mathrm{eV}$ of the adventitious carbon.

Depth profiles were recorded using $\mathrm{Ar}^{+}$-ion beam with the following experimental parameters: argon gas pressure $1.110^{-7}$ mbar, ion energy $3 \mathrm{keV}$, ion current $1 \mu \mathrm{A}$, rastered area $7.5 \times 7.5 \mathrm{~mm}^{2}$. The present spectra of Ce $3 \mathrm{~d}_{3 / 2,5 / 2}$, Si $2 \mathrm{p}$, Lu $4 \mathrm{~d}$, Lu4f, O $1 \mathrm{~s}$ and C $1 \mathrm{~s}$ levels were recorded with a higher pass energy of $50 \mathrm{eV}$, using a smaller spot diameter $(500 \mu \mathrm{m})$ to avoid edge effect of the crater.

Rutherford backscattering spectra were recorded at CERI-CNRS Orleans, France. The equipment consists of a Van-de-Graaff linear accelerator with an energy range from 0.5 to 2.5 $\mathrm{MeV}$. The measurements were carried out with $2 \mathrm{MeV}^{4} \mathrm{He}^{+}$ions. The integrated charge was $20 \mu \mathrm{C}$ and the ion current $15 \mathrm{nA}$. The thin films were about 150-250 nm thick, the RBS measurements probed consequently both the thin films and the underlying substrate since the penetration depth of the ions was several microns. The spectra were analyzed with SIMNRA software version 5.0 [9].

The scintillation spectra were recorded with a Jobin-Yvon Triax 320 monochromator coupled with a CCD camera after excitation of the samples with a tungsten X-ray tube working at $35 \mathrm{kV}$ and $25 \mathrm{~mA}$. The signal was collected near the sample with an optical fiber. 


\section{Results and discussion}

\subsection{X-Ray Diffraction}

Figure 1 presents the $\mathrm{X}$-Ray diffraction patterns recorded for a $\mathrm{Lu}_{0.95} \mathrm{Eu}_{0.05} \mathrm{BO}_{3}$ film prepared by spray pyrolysis.

Rare earth orthoborates can be found with either the calcite or the vaterite structure $[10,11]$. All the recorded diffractograms are identical to the presented one and show exclusively the vaterite form of $\mathrm{LuBO}_{3}$ with no evidence for $\mathrm{LuBO}_{3}$ calcite, $\mathrm{EuBO}_{3}$ or $\mathrm{CeBO}_{3}$ phases. The broad band at $20^{\circ}$ is characteristic of the amorphous silica substrate. The substitution of $\mathrm{Eu}^{3+}$ (or $\mathrm{Ce}^{3+}$ ) for $\mathrm{Lu}^{3+}$ ions in solid solution is thus confirmed.

\section{[Figure 1 around here]}

\subsection{Chemical analysis by XPS and RBS}

XPS spectrum recorded on $\mathrm{Lu}_{0.99} \mathrm{Ce}_{0.01} \mathrm{BO}_{3}$ thin film deposited by a single step spin coating is presented in Figure 2. Cerium concentration has been increased up to $1 \%$ at. (actual optimum concentration for scintillation $0.5 \%$ at.) to decrease the required acquisition times while keeping a value close to the optimum. Photopeaks corresponding to the expected elements are observed together with carbon $\mathrm{C} 1 \mathrm{~s}$ and $\mathrm{Si} 2 \mathrm{~s}$ and $\mathrm{Si} 2 \mathrm{p}$ peaks. The adventitious carbon probably comes from the incomplete decomposition of the alkoxides precursors. The observation of silicon coming from the amorphous silica substrate indicates a very low thickness.

Figure 3 shows the photoelectron spectra of the Ce $3 d_{3 / 2,5 / 2}$ doublet of a spin coated cerium doped film which is compared to the bulk reference $\mathrm{CeO}_{2}$. In the $880-910 \mathrm{eV}$ binding energy range, the components characteristic of $\mathrm{Ce}^{4+}$ overlap those corresponding to $\mathrm{Ce}^{3+}$ and only careful peak decomposition, as already performed by Romeo et al. [12], allows the estimation 
of the contribution of each species. However, for $\mathrm{CeO}_{2}$ (Figure 3 (a)), one single component at $917 \mathrm{eV}$ (peak u'") is observed which is really characteristic of the $\mathrm{Ce}^{4+}$ ion alone. On the borate film this component is slightly visible indicating the presence of cerium at both oxidation states with a majority of $\mathrm{Ce}^{3+}$ ions as previously observed in sol-gel derived films [13]. The XPS analysis of the main core levels of the elements present in the films also gives an estimation of the surface atomic ratios as presented in Table 1.

\section{[Table 1 around here]}

Careful de-convolution of the spectrum in the $185-215 \mathrm{eV}$ region allows to peak the B $1 \mathrm{~s}$ contribution at $192 \mathrm{eV}$ as a shoulder of the $\mathrm{Lu} 4 \mathrm{~d}$ contribution at $196 \mathrm{eV}$. This convolution makes the quantification difficult and can explain the small discrepancies observed between experimental and theoretical values. From the obtained values, the doping with $\mathrm{Ce}^{3+}$ ions appears to be effective and the measured concentration is close to the nominal one.

Figure 4 shows typical depth profiles within the film as obtained by $\mathrm{Ar}^{+}$etching. The surface contamination by $\mathrm{C}$ species resulting from the calcination of organic products initially present in the coating solution decreases rapidly upon etching (from $12 \%$ to less than $1 \%$ after 5 min etching) indicating that the contamination is mainly limited to the top surface of the film. The interface between the borate film and the silica substrate is quite well-defined and the film appears to be homogeneous in a wide range of depth as attested for instance by the Lu $4 \mathrm{f}$ signal. Nevertheless, the profile of the cerium is quite different, for the distribution of $\mathrm{Ce}^{3+}$ ions varies throughout the film with a maximum plateau observed around the middle of the film. However, some diffusion of $\mathrm{Ce}$ into the $\mathrm{SiO}_{2}$ substrate seems to occur as suggested by the nonzero concentration below the film-substrate interface. 
An RBS spectrum measured on a $\mathrm{Lu}_{0.99} \mathrm{Ce}_{0.01} \mathrm{BO}_{3}$ film deposited by 8 consecutive coating steps on a vitreous carbon substrate shows contributions of all the elements of the film (Figure 5). The thickness of the layer and its stoechiometry were extracted from the spectrum. Due to the overlapping of the $\mathrm{Lu}$ and Ce contributions, and the low concentration of cerium, its quantification is difficult and not very accurate but the value has been confirmed by XPS. In addition to the expected elements, a contribution corresponding to $\mathrm{K}$ and $\mathrm{Cl}$ is also observed. This potassium chloride (about 4 at. $\% \mathrm{KCl}$.) is a side product of the methathesis reaction for the preparation of the rare earth alkoxides (see section1). This impurity not observed in XPS measurements could be easily eliminated by careful centrifugation and washing during the synthesis. The atomic ratios of the film derived from the analysis of the RBS spectrum are given in Table 1. The composition is very close to the nominal one. Assuming the density of the film to be the one of the dense orthoborate (7.4), one can also derive the thickness of the film which is $168 \pm 10 \mathrm{~nm}$.

If one looks into details, the complex shape of the spectrum suggests some possible diffusion between the elements of the film and the substrate. A careful fitting has been performed taking into account 15 layers. The first layer is assumed to have the $\mathrm{LuBO}_{3}: \mathrm{Ce}$ composition (see Table 1) whereas layer 15 is the carbon substrate. Intermediate layers (2-14) containing various amount of carbon have been introduced to fit the experimental profile and the final fit is presented in Figure 5. The experimental spectrum is very well reproduced and this confirms the diffusion of carbon in the film. This diffusion might be a consequence of the porous nature of both the carbon substrate and the as deposited sol-gel film. Annealing treatment performed after each coating step would favor the interdiffusion of the two layers and progressive stacking of the layers results in a gradient of carbon in the borate film. It is also worthy to note that, as already mentioned before, some carbon surely comes from the decomposition of the non reacted alkoxides group of the precursors. 


\subsection{Scintillation properties}

The emission spectra have been recorded at room temperature under X-ray excitation for $\mathrm{Eu}^{3+}$ and $\mathrm{Ce}^{3+}$ doped $\mathrm{LuBO}_{3}$ films of vaterite form. Figure 6 (a) displays the scintillation spectrum of $\mathrm{Lu}_{0.995} \mathrm{Ce}_{0.005} \mathrm{BO}_{3}$ obtained under X-Rays excitation. Two bands can be observed in the 350-500 $\mathrm{nm}$ range. These emission bands are characteristics of the $5 \mathrm{~d} \rightarrow{ }^{2} \mathrm{~F}_{7 / 2}$ and $5 \mathrm{~d} \rightarrow$ ${ }^{2} \mathrm{~F}_{5 / 2}$ transitions of $\mathrm{Ce}^{3+}$, which result in an emission of the film in the UV-blue range.

In the case of $\mathrm{Lu}_{0.95} \mathrm{Eu}_{0.05} \mathrm{BO}_{3}$ (Figure 6 (b)), the spectrum is constituted of bands corresponding to ${ }^{5} \mathrm{D}_{0} \rightarrow{ }^{7} \mathrm{~F}_{\mathrm{J}(\mathrm{J}=0-4)}$ transitions of $\mathrm{Eu}^{3+}$ ions as labeled in the figure. The spectral distribution of the $\mathrm{Eu}^{3+}$ doped materials results in a global orange-red emission.

Scintillation yields are difficult to estimate for thin films but the scintillation was high enough to be detected with naked eye confirming the potential use of these films as X-ray converting screens.

\section{Conclusion}

Rare earth doped $\mathrm{LuBO}_{3}$ films have been successfully prepared by the sol-gel process. The composition of the films is very close to the nominal one and doping with rare earth ions is efficient. Carbonaceous residues coming from the precursors are observed essentially in the first atomic layers. Diffusion of Cerium ions towards the silica substrate is observed by XPS and inter-diffusion between the amorphous carbon substrate and the whole layer is evidenced by RBS. The difference in behavior is attributed to the nature of the substrate. The films appear to be homogeneous on a wide range and their scintillation performances are good. These films could be used as interesting alternative solution in X-ray intensifying screens. 


\section{Acknowledgements}

This work was supported by financial support from the French FRT under project LuminiX (RNTS-01B262) and from FNS under “ACI Nanostructures” project LuNaTIC (N5501).

T. Sauvage (CERI-CNRS, Orleans) is acknowledged for access to RBS facilities. The authors thank C. Dujardin (LPCML, Lyon) for fruitful discussions and assistance in measuring the scintillation spectra.

\section{References}

[1] C. Mansuy, J.M. Nedelec, R. Mahiou, J. Mater. Chem., (2004), 14, 3274.

[2] A. Garcia-Murillo, C. Le Luyer-Urlacher, C. Dujardin, C. Pedrini, J. Mugnier, J. Sol-Gel Sci. Techn., (2003), 26, 957.

[3] H. Schmidt, M. Mennig, http://www.solgel.com/articles/Default.htm

[4] L. Zhang, C. Pedrini, C. Madej, C. Dujardin, J.C. Gâcon, B. Moine, I. Kamenskikh, A. Belsky, D.A. Shaw, M.A. MacDonald, P. Mesnard, C. Fouassier, J.C. Van't Spijker, C.W.E. Van Eijk, Radiat. Eff. Defects Solids, (1999), 150(1-4), 439.

[5] M. Balcerzyk, Z. Gontarz, M. Moszynski, M. Kapusta, J. Lumin., (2000), 87-89, 963.

[6] D. Boyer, G. Bertrand-Chadeyron, R. Mahiou, L. Lou, A. Brioude, J. Mugnier, Opt. Mater., (2001), 16, 21.

[7] C. Mansuy, J.M. Nedelec, C. Dujardin, R. Mahiou, J. Sol-Gel Sci. Techn., (2004), 32, 253.

[8] W. Birch, http://www.solgel.com/articles/Default.htm

[9] Mayer M. Technical report IPP 9/113 Max-Planck-Institut fur Plasmaphysik, Garching, Germany, (1997).

[10] E.M. Levin, R.S. Roth, J.B. Martin, American Mineralogist, (1961), 46, 1030.

[11] D. Boyer, F. Leroux, G. Bertrand, R. Mahiou, J. Non-Cryst. Solids, (2002), 306, 110. 
[12] M. Romeo, K. Bak, J. El Fallah, F. Le Normand and L. Hilaire. Surf. Interface Anal. 20 (1993), 508.

[13] J.M. Nedelec, L. Gengembre, S. Turrell, M. Bouazaoui, J. Grimblot, Appl. Surf . Sci., 142 (1999), 243. 


\begin{tabular}{cccc}
\hline Atomic ratio & $\mathrm{B} / \mathrm{Lu}$ & $\mathrm{O} / \mathrm{Lu}$ & $\mathrm{Ce} / \mathrm{Lu}$ \\
\hline XPS & 1.19 & 2.57 & 0.009 \\
RBS & 1.05 & 3.12 & 0.015 \\
Theoretical & 1.01 & 3.03 & 0.01 \\
\hline
\end{tabular}

Table 1: Atomic ratios of a $\mathrm{Lu}_{0.99} \mathrm{Ce}_{0.01} \mathrm{BO}_{3}$ film determined by XPS and RBS.

\section{Figures captions}

Figure 1: X-ray diffraction patterns recorded for $\mathrm{Lu}_{0.95} \mathrm{Eu}_{0.05} \mathrm{BO}_{3}$ film deposited by spray pyrolysis. $\mathrm{LuBO}_{3}$ Vaterite reference pattern is plotted in dotted line.

Figure 2: Global XPS spectrum recorded for $\mathrm{Lu}_{0.99} \mathrm{Ce}_{0.01} \mathrm{BO}_{3}$ film deposited by spin coating (one step).

Figure 3: XPS spectra recorded in the Ce 3d region for a $\mathrm{Lu}_{0.99} \mathrm{Ce}_{0.01} \mathrm{BO}_{3}$ film deposited by spin coating and for $\mathrm{CeO}_{2}$ reference powder.

Figure 4: Concentrations profiles recorded by XPS and ion etching on a $\mathrm{Lu}_{0.99} \mathrm{Ce}_{0.01} \mathrm{BO}_{3}$ film prepared by spin coating (- $\left.\nabla-\mathrm{Lu} 4 \mathrm{~d},-\mathrm{O}-\mathrm{O} 1 \mathrm{~s},-\square-\mathrm{Ce} 3 \mathrm{~d},-\triangle-\mathrm{C} 1 \mathrm{~s},-\frac{\hbar}{\mathrm{s}}-\mathrm{Si} 2 \mathrm{p}\right)$.

Figure 5: RBS spectrum recorded for a $\mathrm{Lu}_{0.99} \mathrm{Ce}_{0.01} \mathrm{BO}_{3}$ film prepared by spin coating ( 8 steps) and corresponding fit (dotted line).

Figure 6: Emission spectra recorded under $\mathrm{X}$-ray excitation for a $\mathrm{Lu}_{0.995} \mathrm{Ce}_{0.005} \mathrm{BO}_{3}$ film (a) and for a $\mathrm{Lu}_{0.95} \mathrm{Eu}_{0.05} \mathrm{BO}_{3}$ film (b) deposited by spray pyrolysis. 


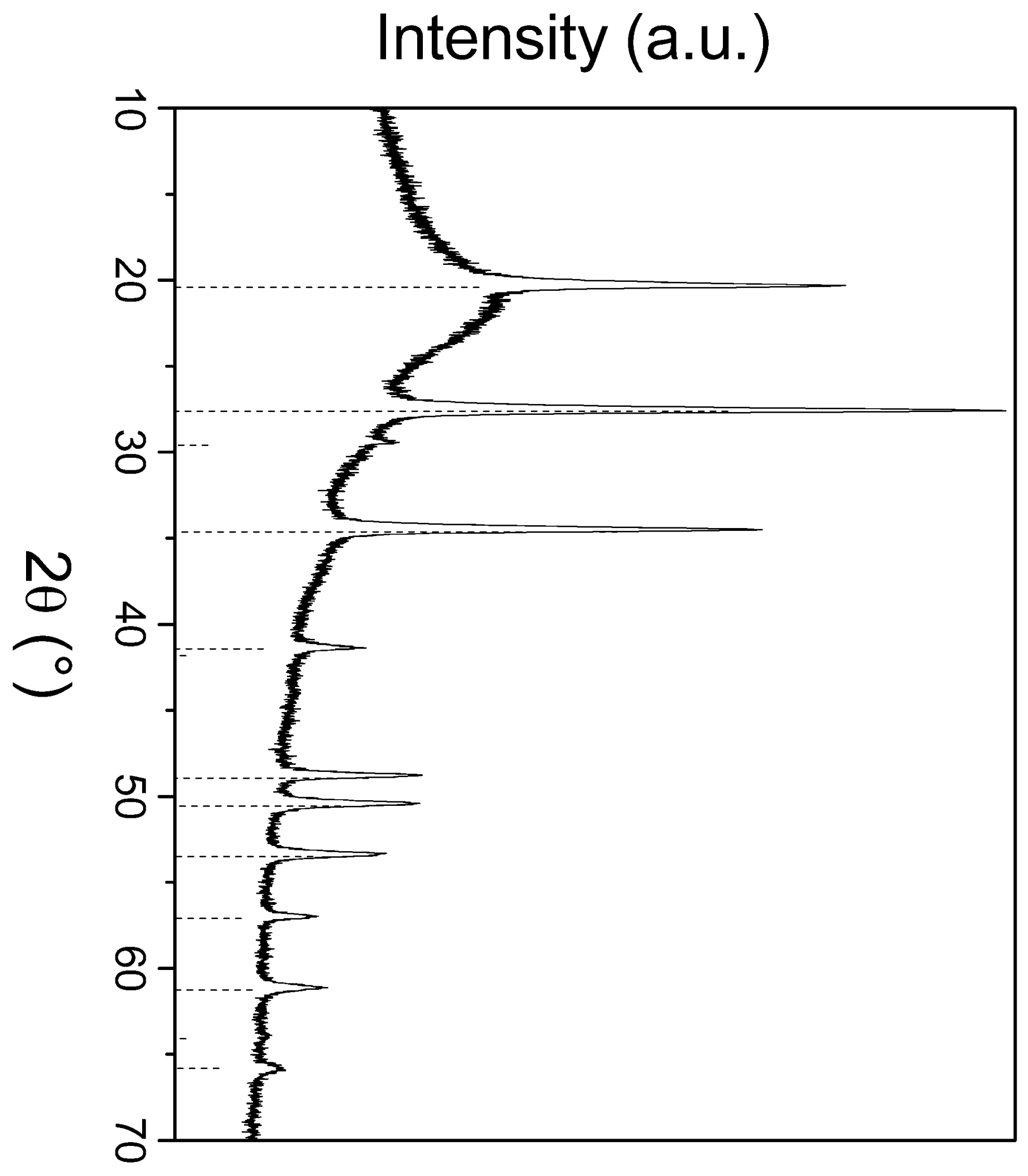


Intensity (a.u.)

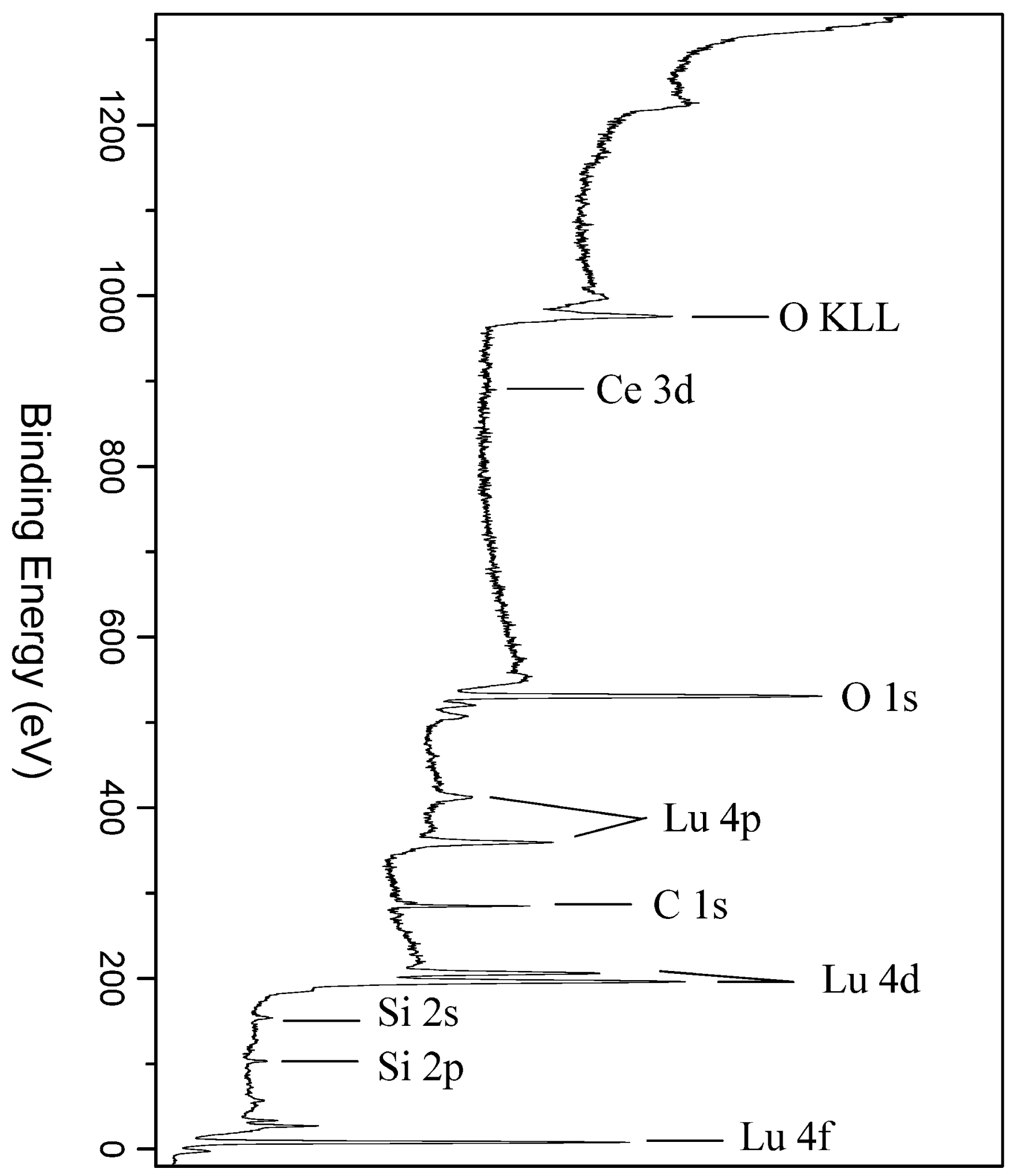




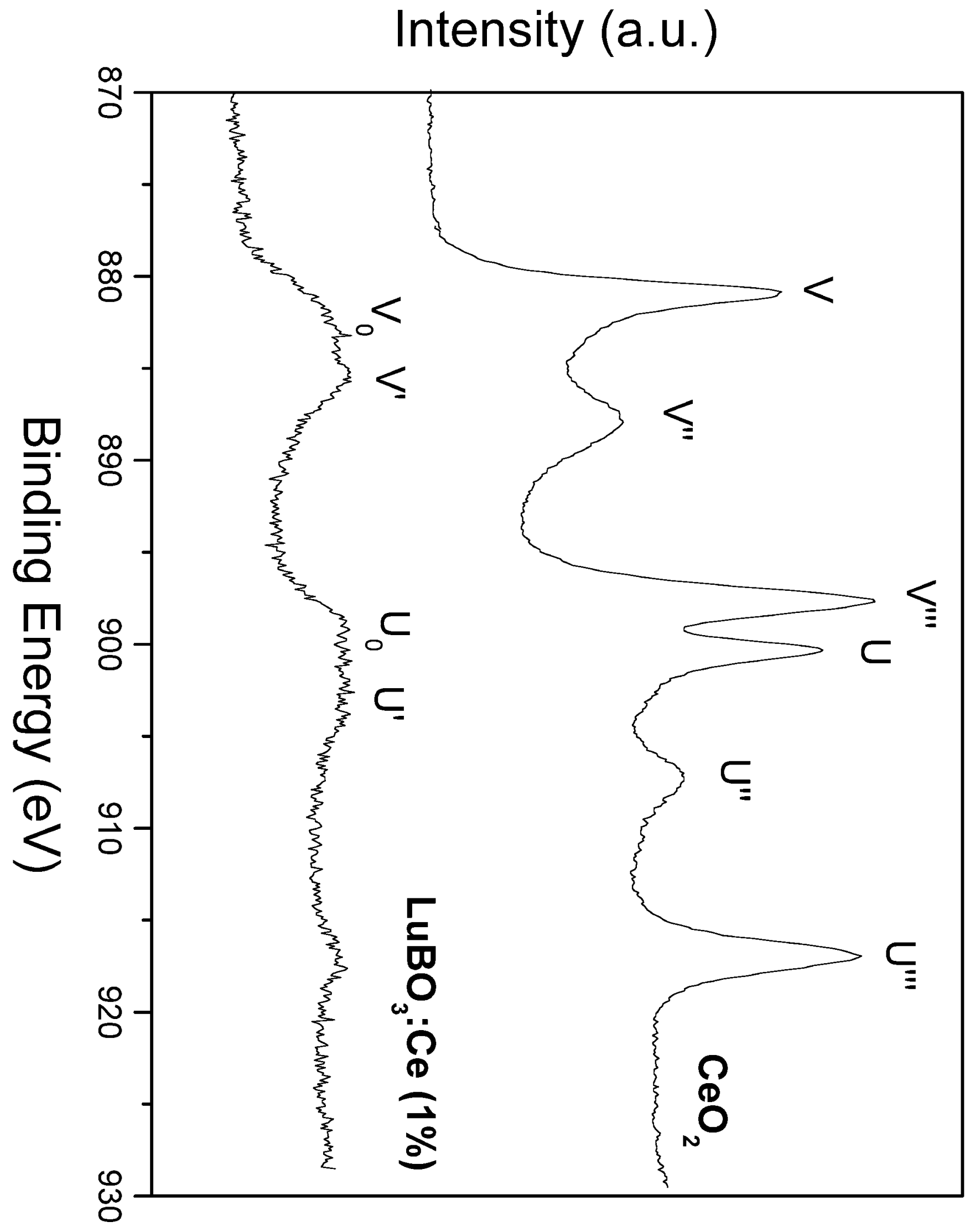


Intensity (a.u.)

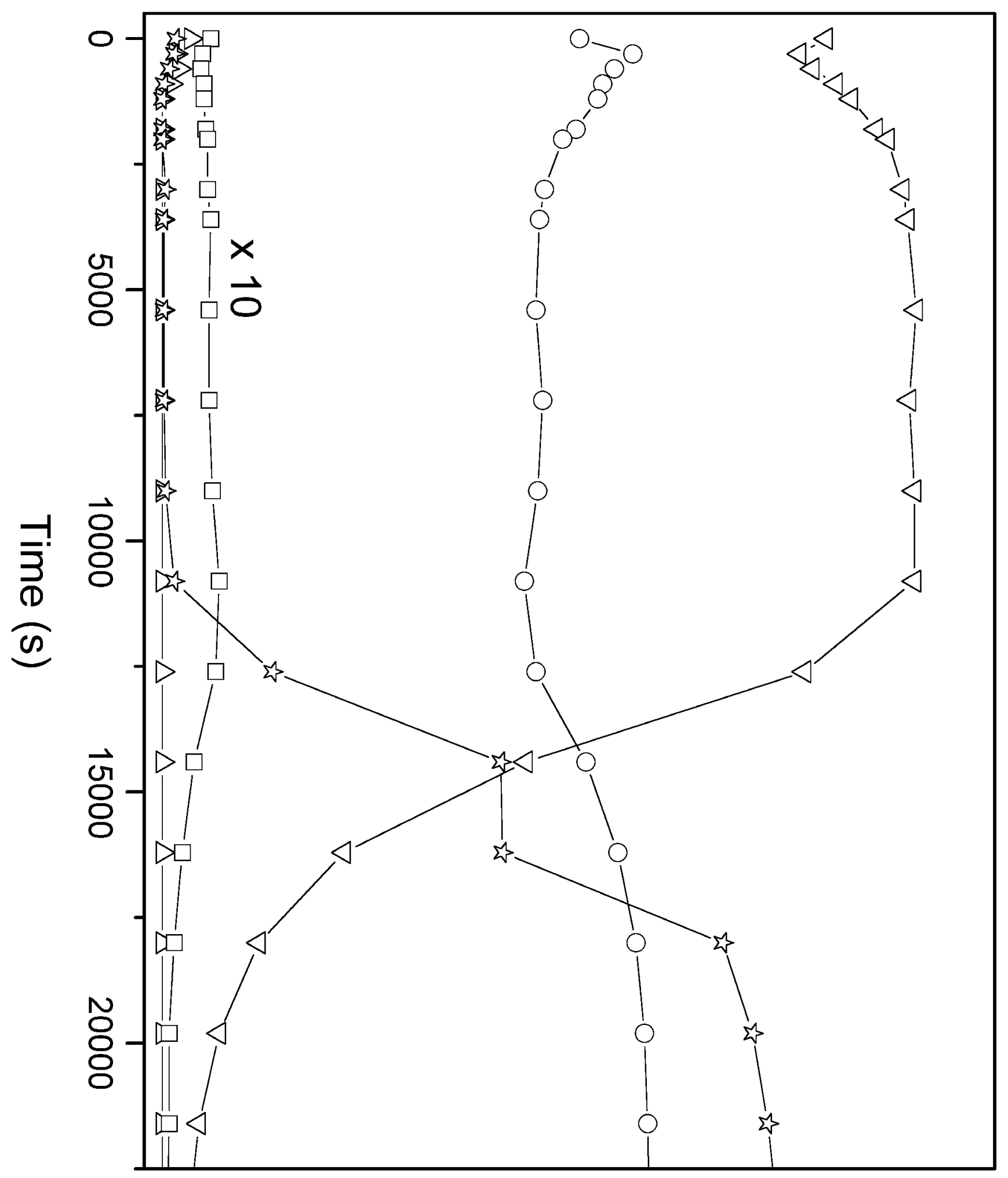




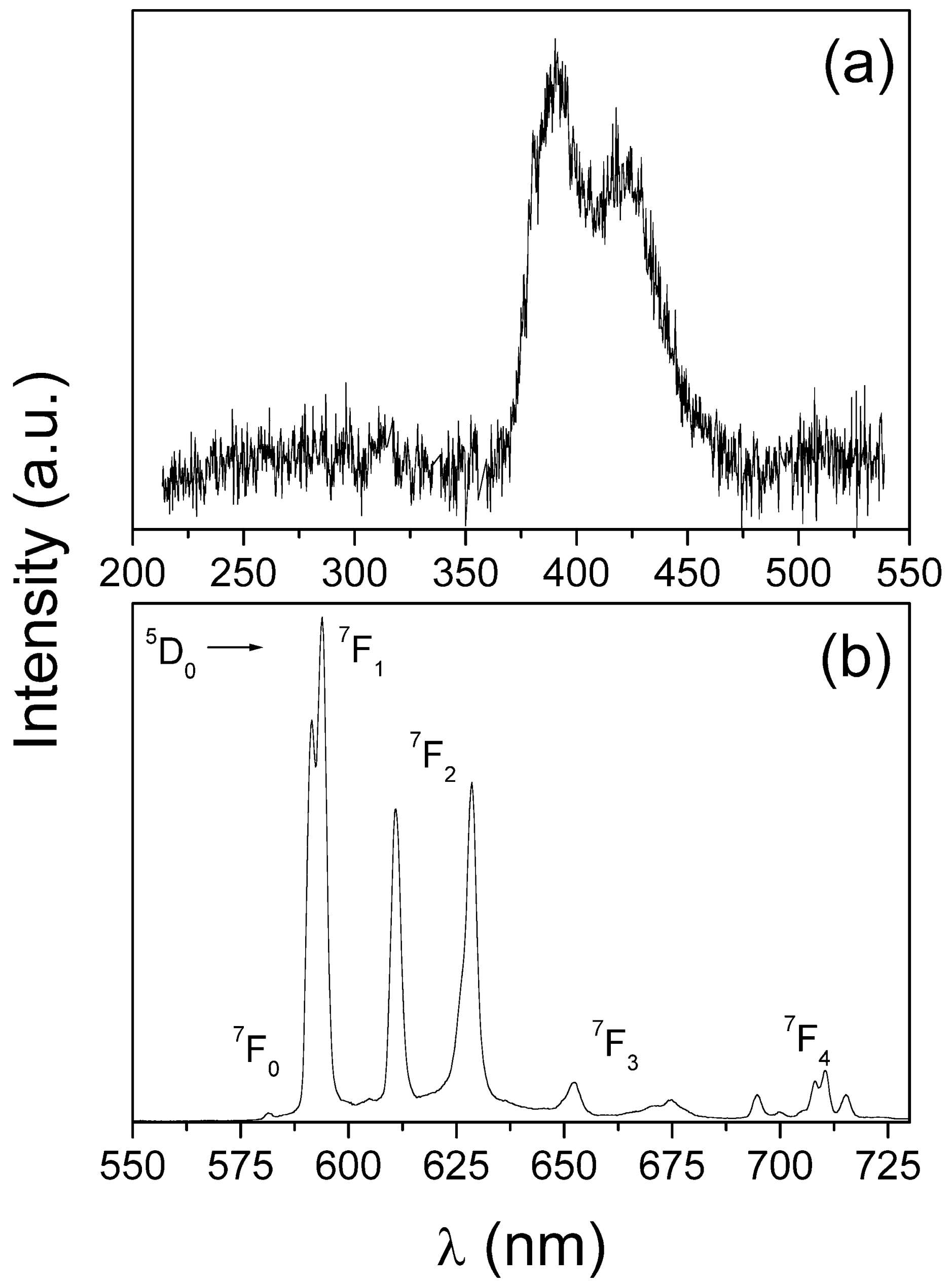

